\title{
Extensive Lipoatrophy on a Buttock Revealing Systemic Lupus Erythematosus Panniculitis
}

YA-CHI LI, MD, Division of Rheumatology/Immunology/Allergy, Department of Internal Medicine, Tri-Service General Hospital, National Defense Medical Center, Taipei, Taiwan; FU-CHIANG YEH, MD, Division of Rheumatology/Immunology/Allergy, Department of Internal Medicine, Tri-Service General Hospital, National Defense Medical Center, Taipei, Taiwan; HSIANG-CHENG CHEN, MD, PhD, Chief, Division of Rheumatology/Immunology/Allergy, Department of Internal Medicine, Tri-Service General Hospital, National Defense Medical Center, Taipei, Taiwan. Address correspondence to Dr. Hsiang-Cheng Chen, Chief, Division of Rheumatology/Immunology/Allergy, Department of Internal Medicine, Tri-Service General Hospital, National Defense Medical Center, No. 325, Sec. 2, Cheng-Gong Rd., Neihu 114, Taipei, Taiwan. E-mail: hccheng@ndmctsgh.edu.tw. J Rheumatol 2016;43:180-1; doi:10.3899/jrheum.150604

Lupus erythematosus panniculitis (LEP) has been reported to be the first manifestation of systemic lupus erythematosus $(\mathrm{SLE})^{1}$. Face and upper limbs are most commonly involved; however, extensive LEP in the buttock region or breasts is relatively rare, but also reported ${ }^{2,3}$. Differential diagnosis such as subcutaneous panniculitis-like $\mathrm{T}$ cell lymphoma should always be considered ${ }^{4}$.

A 41-year-old woman presented with an area of tender swelling on her right buttock, which subsequently shrank forming an extensive depression after 3 months (Figure 1). Arthritis, malar rash, and oral ulcers were also noted. Serological studies showed positive antinuclear antibodies (1:160, nucleolar pattern) and positive anti-dsDNA (14.3 $\mathrm{IU} / \mathrm{ml}$, normal $<10 \mathrm{IU} / \mathrm{ml}$ ). She was diagnosed with SLE since she fulfilled more than 4 criteria of the 1997-revised criteria for the classification of $\mathrm{SLE}^{5}$. Her serum complement levels were within normal range $(\mathrm{C} 3: 113 \mathrm{mg} / \mathrm{dl}$, normal 90-180 mg/dl and C4: $29.6 \mathrm{mg} / \mathrm{dl}$, normal $10-40 \mathrm{mg} / \mathrm{dl}$ ). Magnetic resonance imaging revealed a markedly decreased volume of the subcutaneous fatty layer and thickening over the covering cutis with edema along the lateroposterior site of the right gluteus maximus. A skin biopsy disclosed lobular panniculitis with infiltration of lymphoplasmacytic cells, focal hyaline fat necrosis, and fibrin deposition on the vascular walls (Figure 2). Intravenous methylprednisolone (1 $\mathrm{mg} / \mathrm{kg}$ ) was prescribed for 5 days, followed by oral prednisolone (40 mg/day), hydroxychloroquine ( $200 \mathrm{mg}$ /day), and azathioprine $(100 \mathrm{mg} /$ day $)$ for more than 3 months. The extensive induration extending from her buttock to hip region indicated a poor response to treatment.

\section{REFERENCES}

1. Díaz-Jouanen E, DeHoratius RJ, Alarcón-Segovia D, Messner RP. Systemic lupus erythematosus presenting as panniculitis (lupus profundus). Ann Intern Med 1975;82:376-9.

2. Arai S, Katsuoka K. Clinical entity of lupus erythematosus panniculitis/lupus erythematosus profundus. Autoimmun Rev 2009;8:449-52.

3. Martens PB, Moder KG, Ahmed I. Lupus panniculitis: clinical perspectives from a case series. J Rheumatol 1999:26:68-72.

4. Ma L, Bandarchi B, Glusac EJ. Fatal subcutaneous panniculitis-like T-cell lymphoma with interface change and dermal mucin, a dead ringer for lupus erythematosus. J Cutan Pathol 2005:32:360-5.

5. Hochberg MC. Updating the American College of Rheumatology revised criteria for the classification of systemic lupus erythematosus. Arthritis Rheum 1997;40:1725. 


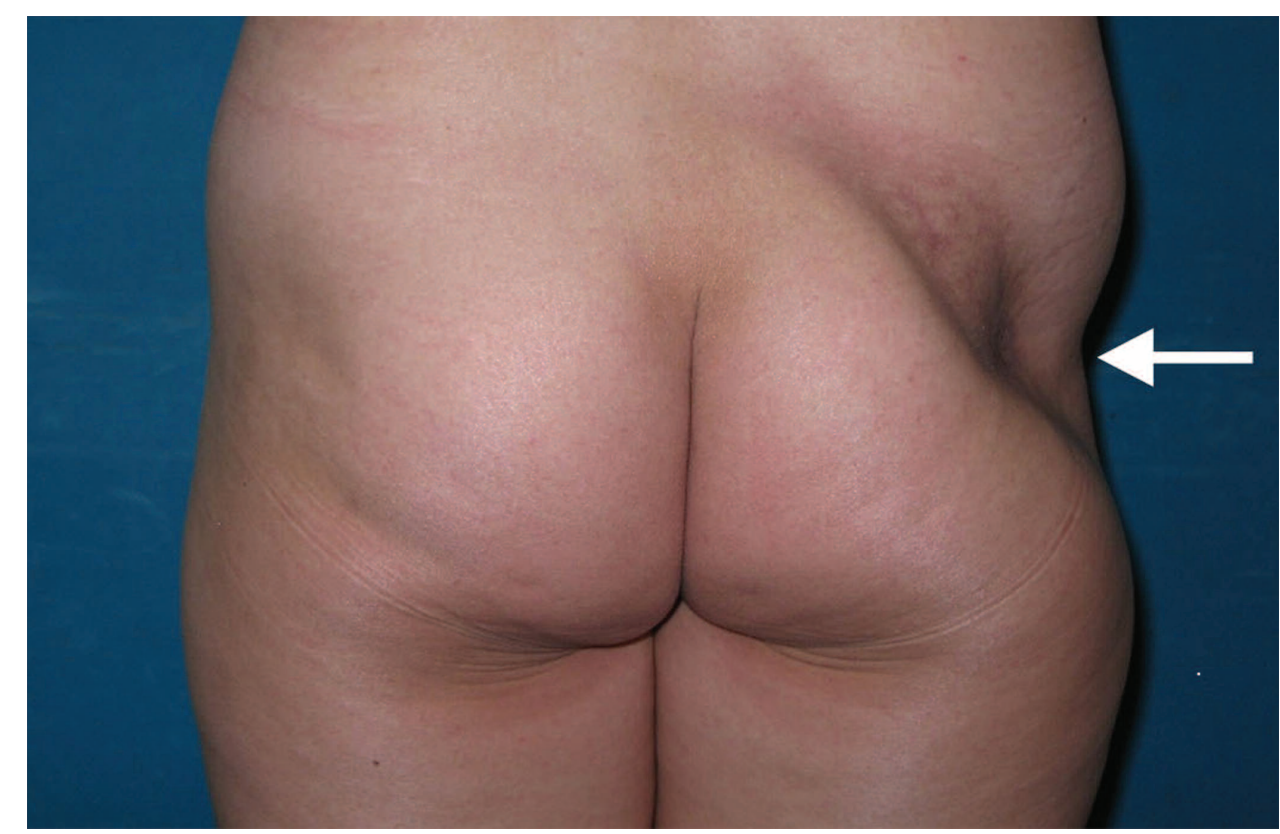

Figure 1. An extensive lipoatrophy presented on the patient's right buttock within 3 months.

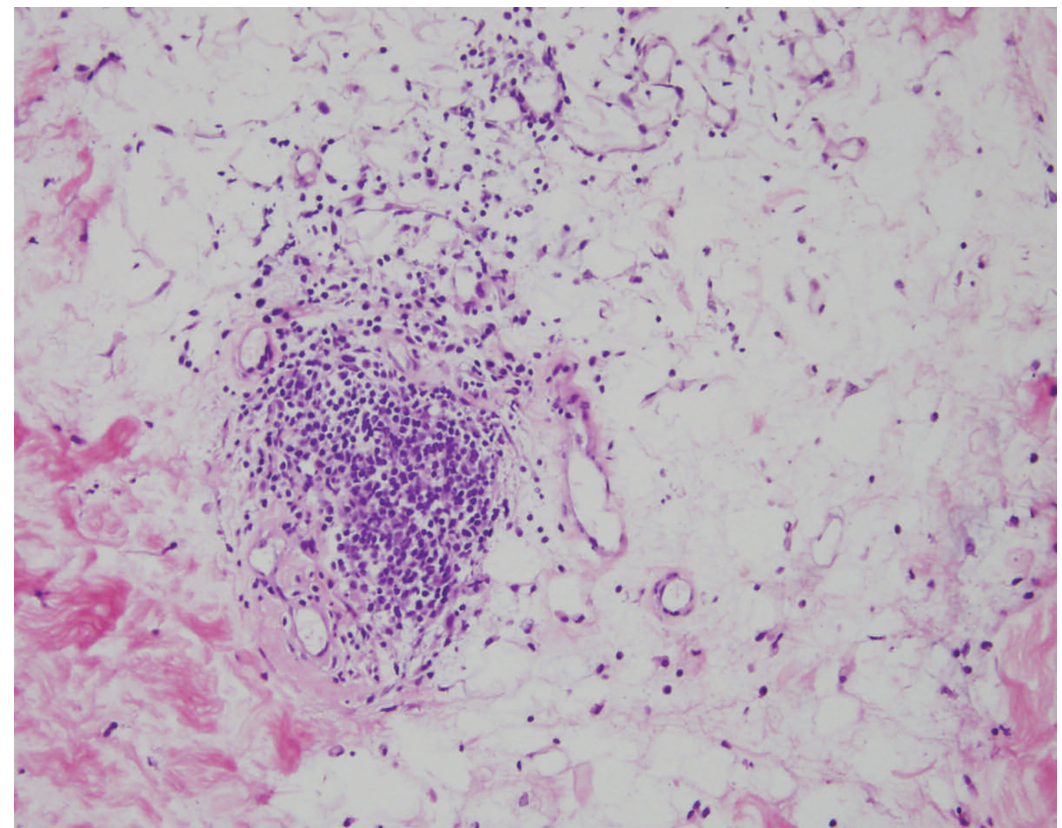

Figure 2. Skin biopsy disclosed lobular panniculitis with infiltration of lymphoplasmacytic cells. 